\title{
The effect of rider weight and additional weight in Icelandic horses in tölt: part II. Stride parameters responses
}

\author{
V. Gunnarsson ${ }^{1 \dagger}$, G. J. Stefánsdóttir ${ }^{1,2}, A$. Jansson ${ }^{1,3}$ and L. Roepstorff ${ }^{3}$ \\ ${ }^{1}$ Department of Equine Science, Hólar University College, IS-551 Sauðárkrókur, Iceland; ${ }^{2}$ Department of Animal Nutrition and Management, Swedish University of \\ Agricultural Sciences, 75007 Uppsala, Sweden; ${ }^{3}$ Department of Anatomy, Physiology and Biochemistry, Swedish University of Agricultural Sciences, 75007 Uppsala, Sweden
}

(Received 29 April 2016; Accepted 19 December 2016; First published online 21 March 2017)

This study investigated the effects of rider weight in the BW ratio (BWR) range common for Icelandic horses (20\% to 35\%), on stride parameters in tölt in Icelandic horses. The kinematics of eight experienced Icelandic school horses were measured during an incremental exercise test using a high-speed camera (300 frames/s). Each horse performed five phases (642 $\mathrm{m}$ each) in tölt at a $B W R$ between rider (including saddle) and horse starting at 20\% (BWR $\left.R_{20}\right)$ and increasing to $25 \%\left(B W R_{25}\right), 30 \%\left(B W R_{30}\right), 35 \%$ $\left(B W R_{35}\right)$ and finally $20 \%\left(B W R_{20 b}\right)$ was repeated. One professional rider rode all horses and weight (lead) was added to saddle and rider as needed. For each phase, eight strides at speed of $5.5 \mathrm{~m} / \mathrm{s}$ were analyzed for stride duration, stride frequency, stride length, duty factor (DF), lateral advanced placement, lateral advanced liftoff, unipedal support (UPS), bipedal support (BPS) and height of front leg action. Stride length became shorter $(\mathrm{Y}=2.73-0.004 \mathrm{x} ; \mathrm{P}<0.01)$ and more frequent $(\mathrm{Y}=2.56+0.002 \mathrm{x} ; \mathrm{P}<0.001)$ with added weight. Duty factor and BPS increased with increased BWR $(\mathrm{P}<0.001)$, whereas UPS decreased $(\mathrm{P}<0.001)$. Lateral advanced timing of limb placement and liftoff and height of front leg action were not affected by BWR (P>0.05). In conclusion, increased BWR decreased stride length and increased DF proportionally to the same extent in all limbs, whereas BPS increased at the expense of decreased UPS. These changes can be expected to decrease tölt quality when subjectively evaluated according to the breeding goals for the Icelandic horse. However, beat, symmetry and height of front leg lifting were not affected by BWR.

Keywords: gait quality, Icelandic horse, rider weight, stride parameters, tölt

\section{Implications}

The Icelandic horse is well known for its tölt and is widespread as a riding horse for leisure and sport. The quality of tölt (e.g. rhythm, stride length, suppleness, front leg action) is of main importance when evaluating Icelandic horses for riding. It is small as a riding horse and the riders are commonly adult. Therefore the BW ratio (BWR) between rider and horse is often high compared with many other riding horses. It is a practical and welfare issue to generate knowledge on how the BW of a rider affects stride parameters in tölt in Icelandic horses.

\section{Introduction}

The influence of rider weight on horse performance and health is a topic of growing interest in the equestrian world. There is limited scientific evidence on the effect of rider weight on stride parameters and gait quality in horses, but some studies report increased relative stride stance time (duty factor (DF)) (Schamhardt et al., 1991; Sloet van

\footnotetext{
† E-mail: vikingur@holar.is
}

Oldruitenborgh-Oosterbaan et al., 1995; De Cocq et al., 2004). Moreover, Matsuura et al. (2013a) observed decreased symmetry of trot with increased rider weight. The Icelandic horse is a gaited horse used for pleasure riding and competitions, with a population of $>200000$ found in over 30 countries (WorldFengur, 2015). Its most distinguished gait is the tölt, one of several lateral four-beat gaits known among the horse breeds of the world (Hildebrand, 1965; Nicodemus and Clayton, 2003). The tölt is a symmetrical four-beat gait, preferably with even intervals between hoof placement and with unipedal support (UPS) (for all limbs) and bipedal support (BPS) (lateral and diagonal), but without suspension. The quality of tölt is subjectively judged at international breeding shows and competitions, and is based on 'clear beat, good balance, harmonic, light and supple movement with long strides, high-front leg action and great speed range' (International Federation of Icelandic Horse Associations (FEIF), 2002 and 2014). The aim of this study was to measure the effect of BWR between rider and horse in the BWR range common for Icelandic horses ( $20 \%$ and $35 \%$ ), on stride parameters in tölt. The starting hypothesis was that increased BWR increases DF, shortens the stride, lowers the 
front leg action, decreases the symmetry of left and right sides and the uniformity of the four-beat tölt.

\section{Material and methods}

The study was approved by the National Animal Research Committee of Iceland.

\section{Horses}

Eight Icelandic riding horses in their summer coat were used (four geldings and four mares, age $17.0 \pm 1.2$ years, range 15 to 19 years). Their mean height at withers was $140 \pm 2 \mathrm{~cm}$ (range 138 to $144 \mathrm{~cm}$ ), body condition score was $3.2 \pm 0.1$ (range 3.0 to 3.25) and BW before feeding in the morning was $366 \pm 15 \mathrm{~kg}$ (range 340 to $382 \mathrm{~kg}$; Smartscale 300; Gallagher USA, New Providence, PA, USA). The horses, all school horses at Holar University College in Iceland with at least 10 years of riding experience, had been used by students in the same teaching program for 9 months before the study began. The management, preparation and training of the horses for the experiment is described in part I. The shoes and boots of all horses were in accordance with international competition rules for Icelandic horses (FEIF, 2014); all horses were shod with $8 \mathrm{~mm}$ shoes on all hooves and had $115 \mathrm{~g}$ boots on front hooves.

\section{Experimental design}

An exercise test with incrementally increased BWR was performed at Hólar University College in early June 2014 on an outdoor $300 \mathrm{~m}$ gravel oval riding track approved for gæðinga competitions (International Federation of Icelandic Horse Associations, 2012). One professional rider (described in part I) rode all the horses on the outer circumference of the track, which corresponded to a distance of $321 \mathrm{~m}$. Each horse performed the exercise test once and all exercise tests were ridden on the left hand and the eight horses were tested over 3 days. The exercise test was preceded by a warm up $(1.1 \pm 0.2 \mathrm{~km})$, consisting of $5 \mathrm{~min}$ of walking on flat gravel surface $(1.0$ to $1.6 \mathrm{~m} / \mathrm{s})$ and $5 \mathrm{~min}$ of slow speed tölt $(1.8$ to $3.1 \mathrm{~m} / \mathrm{s}$ ) in circles of different sizes in both directions (clockwise and counter-clockwise) in the middle of the experimental track. The exercise test was started within 4:18 $\pm 1: 24$ min (mean $\pm S D)$ after the warm up except for one horse, for which it started after 9:25 min because of problems with the equipment. The exercise test consisted of five phases in tölt for two laps per horse, or $642 \mathrm{~m}$ in total, at an average speed of $\sim 5.4 \pm 0.1 \mathrm{~m} / \mathrm{s}$. The incremental factor was BWR between rider (including saddle) and horse, which in each test started at $20 \%\left(\mathrm{BWR}_{20}\right)$ and then increased to $25 \%\left(\mathrm{BWR}_{25}\right), 30 \%\left(\mathrm{BWR}_{30}\right)$ and $35 \%\left(\mathrm{BWR}_{35}\right)$. To evaluate possible effects of cumulative fatigue in the incremental design, each horse finished the test by repeating the $20 \%$ BWR $\left(B W R_{20 b}\right)$. Between phases, the horses were stopped for $5: 26 \pm 1: 13$ min (mean $\pm S D$ ) to add weight. A common Icelandic saddle (Ástund-super; Ástund, Reykjavik, Iceland) was used (described in part I). The rider was instructed to ride the horse in the same manner for all BWR levels, sit fully in the saddle and use minimal aids to ride the horse in balance and with same neck and head carriage, in clear-beat tölt and at the intended speed. The rider dismounted the horses between phases. The horses were health checked before and after the exercise test with no major clinical remarks (described in part I).

\section{Data collection and handling}

The riding track had bars every $107 \mathrm{~m}$ (one-third of the track) of the $321 \mathrm{~m}$ track to facilitate adjustment of the speed and identify start and end of the exercise test. During the exercise test, the rider was coached to keep the intended speed by the timekeeper using wireless intercom. The horses were filmed with a high-speed camera (Casio EX-F1; Casio Computer Co. Ltd, Tokyo, Japan) taking 300 frames/s. The riding track had marking bars every $2 \mathrm{~m}$ for $22 \mathrm{~m}$ on both straight sides of the oval track where the horses were filmed. The camera was mounted on a tripod located in the center of the oval track, $22 \mathrm{~m}$ from the sides and perpendicular to the middle of the marked sides of the track and stayed at the same spot for all tests. For evaluation of stride parameters, the last eight strides filmed for each horse in each phase were used if the speed was consistent, and stride and balance in the gait were considered representative. The average speed at the filmed part was $5.5 \pm 0.1 \mathrm{~m} / \mathrm{s}$. Due to deviations in the consistency of gait and speed, eight strides from another part of the phase were used for one BWR for four horses and for two BWR for one horse. Due to a leg being out of the frame at placement or liftoff, seven strides were used for one BWR for two horses and five and seven strides were used for one BWR for one horse. Film recordings were evaluated in Kinova software (version 0.8 .15 ). Stride duration was measured as the time between successive contacts of the right hind limb. Temporal stride variables were calculated from timing limb placement and liftoff of each foot and expressed as mean percentage of stride duration, as described in the literature (Nicodemus and Clayton, 2003; Clayton, 2004). This was done for DF, UPS, BPS, lateral advanced placement (LAP) and lateral advanced liftoff (LAL). The maximal height of front leg lift was measured as mean angle (degrees) of the eight strides in each phase between the vertical line and the line of the caudal part of the forearm at maximal height of the left front knee. Speed data were taken from the high-speed camera stopwatch, timing the horse on the marked part of the track for the corresponding stride evaluation. Stride length was calculated by dividing speed by stride duration.

Warm up and the exercise test were also videotaped using a digital HD video camera (Sony HDR-CX360VE; Sony Corporation, Tokyo, Japan) for documentation of the whole procedure. The horses in the study were numbered from one to eight and got the same number in both part I and II of the study.

Information on the weather (ambient temperature, relative humidity and wind speed) were collected and described in part I.

\section{Statistical analysis and calculations}

Statistical analysis was performed using SAS (version 9.4; SAS Institute Inc., Cary, NC, USA). Distribution of data were 
verified with Pearson's residual diagnostics to assess the assumptions underlying the analysis. The experimental unit was each horse. Model 1 (PROC MIXED $Y_{i j}=\mu+\alpha_{j}+e_{i j}$ ) was used to analyze differences in stride parameter response between different BWR, where $Y_{i}$ is the observation/ parameter, $\mu$ the mean value, $\alpha_{j}$ the fixed effect of BWR and $e_{i j}$ the residuals $\left(\sim\left(0, \delta^{2}\right)\right)$. Correlations between different BWR for the same horse were estimated using unstructured covariance Model 2 (PROC MIXED $Y_{i j}=\mu+\alpha_{j}+e_{i j}$ ) to analyze the linear relationship between stride parameters and BWR, where $Y_{i}$ is the observation/parameter, $\mu$ the mean value, $\alpha_{j}$ the continuous effect of BWR and $e_{i j}$ the residuals $\left(\sim\left(0, \delta^{2}\right)\right)$. Correlations between different BWR for the same horse were estimated using unstructured covariance Model 3 (PROC MIXED $Y_{i j k}=\mu+a_{i}+(\alpha \alpha)_{i k}+\alpha_{k}+\beta_{j}+(\alpha \beta)_{k j}+e_{i j k}$ ) to analyze differences in stride parameter response between individual limbs or pairs of limbs for different BWR, where $Y_{i j k}$ is the stride observation/parameter, $\mu$ the mean value, $a_{i}$ the random factor of horse, $(a \alpha)_{i k}$ the random factor of horse $x$ BWR interaction, $\alpha_{k}$ the fixed effect of BWR, $\beta_{j}$ the fixed effect of leg (pair of limbs), $(\alpha \beta)_{k j}$ the BWR $\times$ limbs interaction and $e_{i j k}$ the residuals $\left(\sim\left(0, \delta^{2}\right)\right)$. For all models, post hoc comparisons were adjusted for multiplicity using Tukey's method and statistical significance level was set to $P<0.05$. Results based on these models are expressed as least-square means with their root mean square error. Analysis of linear relationship between stride parameters and BWRs (model 2) were based on all the data set but not on mean values. Statistical comparisons of the effect of $\mathrm{BWR}_{20}$ and $\mathrm{BWR}_{20 \mathrm{~b}}$ showed that there were no significant differences in any of the stride parameters indicating no cumulative fatigue in the incremental test and hence BWR $\mathrm{B}_{20 \mathrm{~b}}$ was excluded from the data in the statistical analysis. Descriptive statistics on raw data for relevant variables were expressed as means and standard deviations. Microsoft Excel 2010 (Redmond, WA, USA) was used to calculate the regression coefficient $\left(r^{2}\right)$ between stride variables and BWR level for individual horses. Comparison of linear and polynomial relationship for each variable was used to find the best mean $r^{2}$ for the group of eight horses.

\section{Results}

Mean values for all stride parameters irrespective of BWR are shown in Table 1.

\footnotetext{
Duty factor

Duty factor increased with increased BWR $(P<0.001$, Table 2) and for individual horses this was a positive polynomial relationship (mean \pm SD: $r^{2}=0.91 \pm 0.13$ ). Duty factor was higher in hind limbs than front limbs $(P<0.001$, Table 1$)$ and the difference was not affected by BWR $(P>0.05)$. There was no difference in DF between left and right limbs (42.1 $\pm 1.5 \%$ v. $42.3 \pm 1.6 \%$, respectively, $P>0.05$ ).
}

\section{Limb sequence and timing}

Unipedal support decreased with increasing BWR $(P<0.001$, Table 2). For individual horses this was a negative polynomial
Table 1 Stride parameters (mean $\pm S D$ ) of eight Icelandic horses performing an incremental exercise test (BW ratio between rider and horse increased from $20 \%, 25 \%, 30 \%$ to $35 \%)$ in tölt $(\mathrm{n}=250)^{1}$

\begin{tabular}{lc}
\hline \hline Stride parameters & Mean \pm SD \\
\hline Stride duration (ms) & $475 \pm 9$ \\
Speed (m/s) & $5.5 \pm 0.1$ \\
Stride frequency (strides/s) & $2.11 \pm 0.04$ \\
Stride length (m) & $2.60 \pm 0.07$ \\
Maximal height of front limb (deg) & $93 \pm 5$ \\
Duty factor (DF) (\%) & $42.2 \pm 1.5$ \\
DF front & $39.7 \pm 1.6^{\mathrm{a}}$ \\
DF hind & $44.7 \pm 1.6^{\mathrm{b}}$ \\
Bipedal support (BPS) (\%) & $34.4 \pm 3.1$ \\
BPS lateral & $23.3 \pm 2.9^{\mathrm{a}}$ \\
BPS diagonal & $11.1 \pm 2.0^{\mathrm{b}}$ \\
Unipedal support (UPS) (\%) & $7.8 \pm 1.5$ \\
UPS front & $5.3 \pm 1.6^{\mathrm{a}}$ \\
UPS hind & $10.3 \pm 1.5^{\mathrm{b}}$ \\
Lateral advanced placement (LAP) (\%) & $21.4 \pm 2.1$ \\
LAP left & $21.5 \pm 2.4^{\mathrm{a}}$ \\
LAP right & $21.4 \pm 2.0^{\mathrm{a}}$ \\
Lateral advanced liftoff (LAL) (\%) & $16.4 \pm 1.9$ \\
LAL left & $16.4 \pm 2.1^{\mathrm{a}}$ \\
LAL right & $16.3 \pm 2.0^{\mathrm{a}}$ \\
\hline \hline
\end{tabular}

a,b Means with different superscripts in two adjacent rows within DF, BPS, UPS, LAP and LAL differ significantly $(P<0.05)$.

${ }^{1}$ Total number of strides.

relationship (mean \pm SD: $r^{2}=-0.94 \pm 0.12$ ). Unipedal support was higher for hind limbs than front limbs $(P<0.001$, Table 1) and the difference was not affected by BWR $(P>0.05)$. There was no difference between left and right limbs $(7.9 \pm 1.6 \%$ v. $7.7 \pm 1.6 \%$, respectively, $P>0.05)$. Bipedal support increased with increased BWR $(P<0.001$, Table 2) and for individual horses there was a positive polynomial relationship (mean \pm SD: $r^{2}=0.93 \pm 0.12$ ). Lateral BPS was longer than diagonal BPS $(P<0.001$, Table 1$)$ and the difference was not affected by BWR $(P>0.05)$. There were no effects of BWR on LAP or LAL ( $P>0.05$, Table 2$)$.

\section{Strides, frequency, length, height}

In accordance with the planned experimental set-up, there was no difference in speed of the horses between BWR levels $(P>0.05$, Table 2). Stride duration decreased with increasing BWR $(P<0.001$, Table 2$)$ and there was a positive linear relationship between BWR and stride frequency $(Y=2.56+0.002 x ; P<0.001)$ and a negative linear relationship between BWR and stride length $(Y=2.73-0.004 x$; $P<0.01)$. With a $10 \%$ increase in BWR in the test range $\left(B W R_{20}\right.$ to $\left.B W R_{35}\right)$, stride frequency increased by 0.02 strides/s and stride length decreased by $4 \mathrm{~cm}$. Maximal height of front limbs was not affected by BWR $(P>0.05$, Table 2$)$.

\section{Discussion}

In accordance with our hypothesis, increased BWR caused increased DF, the leg support changed to more BPS and less 
Gunnarsson, Stefánsdóttir, Jansson and Roepstorff

Table 2 Effects of BW ratio (BWR) between rider and horse of 20\% (BWR 20$), 25 \%\left(B W R_{25}\right), 30 \%\left(B W R_{30}\right)$ and $35 \%$ (BWR $\left.R_{35}\right)$ on stride parameters in eight Icelandic horses $(\mathrm{n}=250)^{1}$ in tölt ${ }^{2}$

\begin{tabular}{|c|c|c|c|c|c|}
\hline Stride parameters & $\mathrm{BWR}_{20}$ & $\mathrm{BWR}_{25}$ & $\mathrm{BWR}_{30}$ & $\mathrm{BWR}_{35}$ & RMSE \\
\hline Stride duration (ms) & $478^{a}$ & $475^{a b}$ & $476^{a}$ & $471^{b}$ & 9 \\
\hline Speed $(\mathrm{m} / \mathrm{s})$ & 5.5 & 5.5 & 5.5 & 5.5 & 0.1 \\
\hline Stride frequency (strides/s) & $2.09^{a}$ & $2.11^{\mathrm{ab}}$ & $2.10^{\mathrm{a}}$ & $2.12^{\mathrm{b}}$ & 0.04 \\
\hline Stride length $(\mathrm{m})$ & $2.63^{\mathrm{a}}$ & $2.59^{b}$ & $2.60^{\mathrm{ab}}$ & $2.58^{\mathrm{b}}$ & 0.07 \\
\hline Maximal height of front limb (deg) & 92 & 94 & 92 & 93 & 5 \\
\hline Duty factor $(\%)$ & $40.8^{\mathrm{a}}$ & $42.1^{b}$ & $42.7^{\mathrm{bc}}$ & $43.2^{\mathrm{C}}$ & 1.3 \\
\hline Bipedal support (\%) & $31.6^{\mathrm{a}}$ & $34.1^{\mathrm{b}}$ & $35.4^{\mathrm{bc}}$ & $36.4^{c}$ & 2.6 \\
\hline Unipedal support (\%) & $9.2^{\mathrm{a}}$ & $8.0^{\mathrm{b}}$ & $7.3^{\mathrm{bc}}$ & $6.8^{c}$ & 1.3 \\
\hline Lateral advanced placement (\%) & 21.6 & 22.1 & 20.8 & 21.2 & 2.1 \\
\hline Lateral advanced liftoff (\%) & 16.7 & 17.0 & 15.9 & 15.9 & 2.0 \\
\hline
\end{tabular}

a,b,c Means within rows with different superscripts differ significantly $(P<0.05)$.

${ }^{1}$ Total number of strides.

${ }^{2}$ Values presented as least-square means and root mean square error (RMSE).

UPS and strides became shorter and more frequent. However, other important stride parameters such as symmetry, beat and front leg action were not affected. The increase in DF with added weight confirms findings by Sloet van Oldruitenborgh-Oosterbaan et al. (1995) and De Cocq et al. (2004). The increase was proportionally the same for all limbs and hence it is likely that the added weight was close to the vertical line of gravity. This seems logical for the short-backed Icelandic horse and even though the saddle might have been located slightly in front of this line, the horse and rider appeared able to compensate for the difference. Similarly, Schamhardt et al. (1991) reported that a load in the saddle increased ground reaction forces more in front limbs than hind limbs, but a rider shifted position of their center of mass toward the hind limbs compared with a static weight of the same mass. The higher DF in hind than front limbs observed in the present study has been reported in other studies on lateral gaits (Hildebrand, 1989; Robilliard et al., 2007) and illustrates the important weight-carrying role of the hind limbs for balance in tölt, which should predispose for valuable self-carriage in the gait. The relationship between increased BWR and DF for seven horses studied was a polynomial curve with a slightly convex shape, which might indicate that at the highest BWR they were approaching the natural limits of maximal DF in tölt at $5.5 \mathrm{~m} / \mathrm{s}$ and in the LAP range measured. However, one horse (number 6) did not show much difference in DF until BWR ${ }_{35}$ so there were individual differences in weight-bearing responses within the group of horses studied.

The increase in DF with added weight in this study was due to increased BPS as UPS decreased, and can be explained as compensation by the horse to increase its stability and balance in tölt. However, the difference in lateral $v$. diagonal BPS was kept unchanged with added weight, as reflected in unaffected LAP and LAL. Unipedal support decreased by about $25 \%$ (from $9.2 \%$ to $6.8 \%$ ) between $\mathrm{BWR}_{20}$ and $\mathrm{BWR}_{35}$ and this change was proportionally the same in hind and front limbs. Strides with tripedal support were not expected at the speed used in the study $(5.5 \mathrm{~m} / \mathrm{s})$, as this is generally associated with tölt at slower speeds, as reported by Nicodemus and Clayton (2003). However, minor tripedal support $(3 \mathrm{~ms})$ was found in three strides in one horse (number 3 ) at $\mathrm{BWR}_{35}$, which could be explained as an extreme incident in addition to the general increase in DF and BPS with added weight. There were no examples of suspension in the study, although suspension is well known at similar speeds in tölt (Zips et al., 2001), but is regarded as a fault in the official definition of the gait (FEIF, 2002).

The LAP and LAL were not affected by BWR. The LAP measurement of $21 \%$ in this study was slightly more lateral than a perfectly even four-beat tölt, which has LAP of $25 \%$. Our value was similar to the $22 \%$ LAP observed in tölt in Icelandic riding school horses in 2010 (Gunnar Reynisson, personal communication), but lower than the slightly diagonal 29\% LAP observed by Nicodemus and Clayton (2003) in Icelandic horses at slow speed in tölt and higher than 18\% LAP reported by Zips et al. (2001) in Icelandic horses at speed of $4.7 \mathrm{~m} / \mathrm{s}$ in tölt. Lateral sequence single-foot gaits have been defined as occurring within a LAP range of $25 \pm 6 \%$ (Hildebrand, 1989; Reilly and Biknevicius, 2003). The lower value of LAL compared with LAP in our study (16\% and $21 \%$, respectively) reflects the higher DF of hind limbs compared with front limbs, but also implies that the limb liftoff movements might be perceived as more lateral to watch than the sound of the beat (hoof placement).

All eight horses studied were symmetrical between left and right limbs, with no difference in any of the stride parameters measured. This was not affected up to the highest BWR (35\%) tested in the present study, but elsewhere, BWR values of $29 \%$ (Matsuura et al., 2013a) and 43\% (Matsuura et al., 2013b) have been reported to cause a significant decrease in stride symmetry in trot $(3 \mathrm{~m} / \mathrm{s})$ in studies on native Japanese horses and Taishuh ponies, respectively.

Strides became slightly shorter with increased BWR, which might be a locomotor response of the horse in order to maintain its balance when ridden at the same speed. The increased DF and shorter strides with increased BWR found in 
this study were probably reflected in proportionally increased retraction time of the front limbs. This corresponds to the response reported to occur with added load at trot (De Cocq et al., 2004), when the liftoff of the front limbs occurs in a more rearward position to get prolonged support for the trunk in each stride. However, other studies have reported that despite higher DF with increased load, there were no effects on stride length (Sloet van OldruitenborghOosterbaan et al., 1995; Matsuura et al., 2013a). A possible reason for this discrepancy in results could be the considerably lower speed used in the latter studies, some differences between responses in tölt and trot and use of a treadmill in one study.

According to the basic laws of physics, the energy cost in all gaits can be expected to increase with increased BWR. In this study, higher DF and shorter strides were observed with increased BWR at the same speed and gait, and thus these stride parameters can be expected to be indicators within a horse of workload and energy expenditure. The natural instinct of the horse to move in an economical way (Hoyt and Taylor, 1981) might actually be one of the reasons for these changes in stride parameters, together with the importance to maintain its balance. Direct comparison of physiological parameters and stride parameters is needed to investigate this relationship.

The stride parameters measured in this study are related to quality of tölt as described in the breeding standards (FEIF, 2002) and rules for competitions (FEIF, 2014) for Icelandic horses. The increased DF at the same speed in tölt found in this study can be expected to appear as more 'earth-bound' movements. The UPS in the hind limbs is the same interval of the stride as half suspension in the front limbs (both front limbs off the ground at the same time) and vice versa. Half suspension gives the highly appreciated lightness and 'air' in the movement, so increased DF and a shift from UPS to BPS with increased BWR will predispose to decreased quality of the gait. Similar effects occur with decreased stride length, which in itself is a valuable trait of tölt quality but is also linearly related to speed (Biknevicius et al., 2004; Robilliard et al., 2007) and may therefore decrease maximum speed in the gait. In addition to these changes in measured stride parameters, the increased BWR might affect the topline of the horses negatively when ridden, as a load on the back of the horse has been reported to cause increased back extension in walk, trot and canter (De Cocq et al., 2004). However, this has not been reported in tölt, but the effect might appear as a forwardsloping line from the highest point of the croup to the deepest point of the back, which makes the horse look higher at the croup and heavier at the front. On the other hand, the highly valued traits in tölt of symmetry of left and right sides (DF, LAP and LAL), beat of the gait and height of front leg action were not affected by the range of BWR tested in this study. None of the stride parameters measured in this study indicated increased quality of tölt with increased BWR. It was beyond the scope of the analysis to compare the changes in stride parameters against subjective judgments, but such comparisons might reveal ways to improve current judging methods.
Concerning the design of the study, the relatively short distance ridden in each phase $(642 \mathrm{~m})$ with a few minutes' pause between phases avoided significant cumulative fatigue, which would have made it difficult to isolate direct effects of BWR in the study. Veterinary health checks before and after the test, the observed physiological recovery of the horses (part I) and no difference in stride parameters between $\mathrm{BWR}_{20}$ and $\mathrm{BWR}_{20 \mathrm{~b}}$ showed that they coped well with the test, apart from a temporary muscle tremor in one horse (number 2). Regarding the effect of BWR on the health of horses observed in this study, note that these results are only valid for Icelandic horses at the speed and distance used here and not over a longer distance, for different speeds or for long-term health. It must also be emphasized that the horses had all been professionally trained in tölt for several years and were known to have a symmetrical, stable and fairly even four-beat tölt, although they were not classified as elite competition horses. A minority of Icelandic horses are natural tölters that have a stable and even four-beat in tölt from the start of their training, but more commonly they tend to be either somewhat pacey (too lateral) or trotty (too diagonal) until after a considerable amount of training. Response to this exercise test might differ significantly in younger horses because of their lower muscular strength and generally poorer balance in tölt. Symmetry and beat of the tölt did not change throughout the exercise test which indicates that the riders balance was not interrupted by added weight and the total weight was stable and moved in harmony with the horse. A less experienced and unbalanced rider might interfere with this harmony, as has been reported for other gaits (Peham et al., 2001; Lagarde et al., 2005) and the disruptive effect for the horse would be expected to increase with increasing weight of the rider. However, the soft and steady seat in tölt (Biknevicius et al., 2006) should in general predispose for a less disruptive influence of rider weight compared with the bouncing movement in gaits with suspension, such as trot and pace. One more shortcoming of the experimental design was that the horses were only filmed on a straight line and not on the curves of the track, which could have influenced their balance and stride parameters differently. Most competition disciplines with Icelandic horses are executed on an oval track (FEIF, 2014), but breeding evaluations and racing are conducted on a straight track (FEIF, 2002 and 2014).

There are no simple answers to the relevant question of weight-bearing capacity of riding horses. In light of the results from this study on symmetry of left and right limbs, beat of the gait and height of front leg action, it can be speculated that the weight-bearing capacity of Icelandic horses is at least $35 \%$ BWR in middle tempo tölt. However, several stride parameters changed significantly in the BWR range $20 \%$ to $35 \%$. For a better understanding of the weightbearing abilities of horses and effects of rider weight and riding technique on biomechanical, physiological and health aspects, much more research is needed. This should include comparisons of different speeds, distances, gaits and track surfaces and determination of the effects of age, 
training, breed and conformation. Such knowledge is essential for improvements and guidelines in the diverse field of horse training and riding.

In conclusion, increasing BWR from $20 \%$ to $35 \%$ did not affect beat, symmetry and height of front leg lift in tölt. However, it decreased stride length, increased DF, proportionally to the same extent on all limbs, and increased BPS at the expense of decreased UPS. These changes can be expected to lower the quality of tölt by appearing as heavier movements and shorter strides when evaluated subjectively. If increased DF, number of strides and shorter strides have any implication for horse's welfare it needs further investigation.

\section{Acknowledgments}

The authors want to sincerely thank the research team at Hólar in June 2014 for their valuable work and cooperation. Ulf Olsson and Claudia Brömssen get thanks for statistical help. This project was funded by the Stock Protection Fund of the Icelandic horse, the Developmental Fund of the Icelandic Horse Breeding, the Pálmi Jónsson Natural Conservation Fund and Hólar University College.

\section{References}

Biknevicius AR, Mullineaux DR and Clayton HM 2004. Ground reaction forces and limb function in tölting Icelandic horses. Equine Veterinary Journal 36, 743-747.

Biknevicius AR, Mullineaux DR and Clayton HM 2006. Locomotor mechanics of the tölt in Icelandic horses. American Journal of Veterinary Research 67, 1505-1510.

Clayton H 2004. The dynamic horse. Sport Horse Publications, Mason, MI, USA. De Cocq P, van Weeren PR and Back W 2004. Effects of girth, saddle and weight on movements of the horse. Equine Veterinary Journal 36, 758-763.

International Federation of Icelandic Horse Associations (FEIF) 2002. FEIF rules for Icelandic horse breeding (FIZO). Retrieved on 17 November 2015 from http://feiffengur.com/documents/fizo14.pdf.
International Federation of Icelandic Horse Associations 2012. Prefix to the 'gæðingakeppni'. Retrieved on 13 February 2015 from http://www.feiffengur. com/documents/G\%C3\%A6\%C3\%BOingakeppni\%202012.pdf.

International Federation of Icelandic Horse Associations (FEIF) 2014. FEIF rules for Icelandic horse sport events (FIPO). Retrieved on 13 February 2015 from http://www.feiffengur.com/documents/fipo2014.pdf.

Hildebrand M 1965. Symmetrical gaits of horses. Science 150, 701-708.

Hildebrand M 1989. The quadrupedal gaits of vertebrates. Bioscience 39, 766-775.

Hoyt DF and Taylor CR 1981. Gait and the energetics of locomotion in horses. Nature 292, 239-240.

Lagarde J, Kelso JA, Peham C and Licka T 2005. Coordination dynamics of the horse-rider system. Journal of Motor Behavior 37, 418-424.

Matsuura A, Irimajiri M, Matsuzaki K, Hiraguri Y, Nakanowatari T, Yamazaki A and Hodate K 2013a. Method for estimating maximum permissible load weight for Japanese native horses using accelerometer-based gait analysis. Animal Science Journal 84, 75-81.

Matsuura A, Sakuma S, Irimajiri M and Hodate K 2013b. Maximum permissible load weight of a Taishuh pony at a trot. Journal of Animal Science 91, 3989-3996.

Nicodemus MC and Clayton HM 2003. Temporal variables of four-beat, stepping gaits of gaited horses. Applied Animal Behaviour Science 80, 133-142.

Peham C, Licka T, Kapaun M and Scheidl M 2001. A new method to quantify harmony of the horse-rider system in dressage. Sports Engineering 4, 95-101.

Reilly SM and Biknevicius AR 2003. Integrating kinetic and kinematic approaches to the analysis of terrestrial locomotion. In Vertebrate biomechanics and evolution (ed. VL Bels, JP Gasc and A Casinos), pp 243-265. Bios Scientific Publishers, Oxford, UK.

Robilliard JJ, Pfau T and Wilson AM 2007. Gait characterization and classification in horses. Journal of Experimental Biology 210, 187-197.

Sloet van Oldruitenborgh-Oosterbaan MM, Barnevald A and Schamhardt HC 1995. Effects of weight and riding on workload and locomotion during treadmill exercise. Equine Veterinary Journal 18, 413-417.

Schamhardt HC, Merkens HW and van Osch GJ 1991. Ground reaction force analysis of horses ridden at the walk and trot. In Proceedings of the 3rd International Conference on Equine Exercise Physiology, Uppsala, Sweden, 15-19 July 1990 (ed. SGB Persson, A Lindholm and LB Jeffcott), pp. 120-127. ICEEP Publications, Davis, CA, USA

WorldFengur 2015. The studbook of origin for the Icelandic horse. Retrieved on 28 April 2015 from www.worldfengur.com.

Zips S, Peham C, Scheidl M, Licka T and Girtler D 2001. Motion pattern of the toelt of Icelandic horses at different speeds. Equine Veterinary Journal 33 (suppl. 33), 109-111. 